\title{
Rebound Thrombocytosis following Induction Chemotherapy Is an Independent Predictor of a Good Prognosis in Acute Myeloid Leukemia Patients Attaining First Complete Remission
}

\author{
Umit Yavuz Malkan Gursel Gunes Ayse Isik Eylem Eliacik Sezgin Etgul \\ Tuncay Aslan Muruvvet Seda Balaban Ibrahim Celalettin Haznedaroglu \\ Haluk Demiroglu Hakan Goker Osman Ilhami Ozcebe Nilgun Sayınalp \\ Salih Aksu Yahya Buyukasik \\ Department of Hematology, School of Medicine, Hacettepe University, Ankara, Turkey
}

\section{Key Words}

Acute myeloid leukemia · Good prognosis · Independent predictor $\cdot$ Rebound thrombocytosis

\begin{abstract}
There are very few data about the relationship between acute myeloid leukemia (AML) prognosis and bone marrow recovery kinetics following chemotherapy. In this study, we aimed to assess the prognostic importance and clinical associations of neutrophil and platelet recovery rates and rebound thrombocytosis (RT) or neutrophilia (RN) in the postchemotherapy period for newly diagnosed AML patients. De novo AML patients diagnosed between October 2002 and December 2013 were evaluated retrospectively. One hundred patients were suitable for inclusion. Cox regression analysis using need for reinduction chemotherapy as a stratification parameter revealed RT as the only parameter predictive of OS, with borderline statistical significance ( $p=$ $0.06, \mathrm{OR}=7 ; 95 \% \mathrm{Cl} 0.92-53)$, and it was the only parameter predictive of DFS $(p=0.024, O R=10 ; 95 \% \mathrm{Cl} 1.3-75)$. In order to understand whether RT or RN was related to a better mar-
\end{abstract}

row capacity or late consolidation, we considered neutrophil recovery time and platelet recovery time and nadir-first consolidation durations in all patients in the cohort. Both the marrow recovery duration and the time between marrow aplasia and first consolidation were shorter in RT and RN patients. To our knowledge, this is the first study to report a correlation between RT/RN and prognosis in AML.

(C) 2015 S. Karger AG, Basel

\section{Introduction}

Outcome prediction in acute myeloid leukemia (AML) is vital since most patients fail to be cured primarily because of resistance to therapy. The clinical outcomes of individual AML patients vary across a wide spectrum, ranging from living just a few days to cure of the disease $[1,2]$. The prognosis of AML and the resistance to treatment could be predicted via clinical, cytogenetic, and molecular diagnostic methods [1,3-7]. Resistance prediction in AML is extremely important for critical therapeutic decisions and follow-up of the patient [7]. The ability

\begin{tabular}{ll}
\hline KARGER 125\% & $\begin{array}{l}\text { (1) 2015 S. Karger AG, Basel } \\
0001-5792 / 15 / 1341-0032 \$ 39.50 / 0 \quad \text { Karger }\end{array}$ \\
$\begin{array}{l}\text { E-Mail karger@karger.com } \\
\text { www.karger.com/aha }\end{array}$ & $\begin{array}{l}\text { This is an Open Access article licensed under the terms of the } \\
\text { Creative Commons Attribution-NonCommercial 3.0 Un- } \\
\text { ported license (CC BY-NC) (www.karger.com/OA-license), } \\
\text { applicable to the online version of the article only. Distribu- } \\
\text { tion permitted for non-commercial purposes only. }\end{array}$
\end{tabular}

Umit Yavuz Malkan

Mutlukent Mahallesi

Mutluköy Sitesi 1951, Sokak, No: 6, Ümitköy

TR-6800 Ankara (Turkey)

E-Mail umitmalkan@hotmail.com 
to predict therapeutic resistance in AML is still based on the routinely available clinical covariates even in the presence of the most skilled advanced molecular methods [7]. The relationship between a poor prognosis and residual blasts 7-10 days after AML induction chemotherapy is well known, and this evaluation is widely applied in clinical practice for early reinduction [8].

There are very few data about the relationship between AML prognosis and bone marrow recovery kinetics following chemotherapy $[9,10]$. Thrombocytopenia, platelet recovery, thrombopoietin (TPO), and thrombocytosis may be related to the clinicopathological course of AML $[11,12]$. The aim of this study is to assess the prognostic importance and clinical associations of neutrophil and platelet recovery rates and rebound thrombocytosis (RT) or neutrophilia (RN) in the postchemotherapy period in newly diagnosed AML patients. Elucidation of the interrelationships between the cellular postchemotherapy recovery kinetics of bone marrow and the prognosis of AML is important for therapeutic decisions of patients during the long-term clinical course of AML.

\section{Patients and Methods}

De novo AML patients diagnosed between October 2002 and December 2013 were evaluated retrospectively. They were prospectively recorded during clinical follow-up. All of the studied patients with AML received induction/reinduction chemotherapy protocols and other diagnostic/therapeutic standard clinical interventions if there was an absolute clinical indication at the given disease state(s). Meanwhile, all of the ethical considerations were strictly handled in accordance with the Helsinki Declaration. As a standard of care/action of the hospitals of Hacettepe Medical School, it was confirmed based on patient records that all of the study patients gave informed consent at the time of hospitalization and before the administration of chemotherapy and other relevant diagnostic/therapeutic standards of care. Patients who attained first complete remission (CR) after 1 or 2 intensive induction therapies were selected and their marrow aplasia periods preceding CR were considered. Patients who had received a transplant were excluded. Also, patients with a postinduction recovery period maximum platelet count $<100 \times 10^{9} / 1$ or a neutrophil count $<1.5 \times 10^{9} / 1$ were excluded considering the possibility of incomplete marrow recovery before consolidation therapy. Neutrophil (NRT) and platelet recovery times (PRT) were accepted as the periods between a neutrophil nadir and a neutrophil count $\geq 1 \times 10^{9} / 1$ and a platelet nadir and a platelet count $\geq 50 \times 10^{9} / 1$, respectively. The platelet nadir-to-first consolidation and neutrophil nadir-to-first consolidation times were computed. RN and RT thresholds were accepted as $7 \times 10^{9} / \mathrm{l}$ and $450 \times 10^{9} / \mathrm{l}$, respectively. Various cut-off levels above these values were tried. Primary endpoints for this study were disease-free survival (DFS) and overall survival (OS). OS was calculated from diagnosis to the date of death due to any cause.

RT Is a Predictor of Prognosis in AML
DFS was analyzed in CR patients from the date of CR attainment to relapse or death in remission. Patients who did not die and those who did not relapse or die during the first CR were censored at the last follow-up for OS and DFS computations, respectively. Age, gender, histological subtype of leukemia, baseline ECOG performance score, white blood cell count (WBC), need for reinduction chemotherapy, ELN cytogenetic subgroup, residual disease in interim marrow assessment, RT, and RN were evaluated as possible prognostic parameters for OS and DFS.

Categorical and continuous data were compared using a $\chi^{2}$ test (or Fisher's exact test if required by the sample size) and an independent-samples t test, respectively. Bivariate correlation analysis for categorical variables was done using Spearman's correlation analysis. Survival analyses were computed via the Kaplan-Meier method. Comparisons of survival rates were done using a log-rank test. Univariate comparisons with a $\mathrm{p}$ value $<0.1$ were included in multivariate analyses in which $\mathrm{p}<0.05$ was considered statistically significant. Cox regression analysis was used to study the simultaneous effect of selected variables on survival. Statistical Package for the Social Sciences v17.0 (SPSS Inc., Chicago, Ill., USA) software was used for statistical analyses.

Survival analyses were performed both in all patient cohorts and in cytogenetically homogeneous subgroups, acute promyelocytic leukemia (APL), CBF-type leukemia, and others in order to understand the prognostic value of RT/RN in specific subgroups.

\section{Results}

One hundred patients were suitable for inclusion. The median follow-up time was 23.8 months (range 1.3$119.5)$ for 64 surviving patients. The main baseline characteristics of the patients are presented in table 1. Except for rare cases, anthracycline-cytarabine $3+7$ was applied in non-APL patients as the induction chemotherapy protocol. The induction protocol comprised idarubicin and all-trans-retinoic acid in APL cases. Non-APL patients received 2-4 high-dose cytarabine or rarely repeated anthracycline-cytarabine courses for consolidation. Three ATRA-anthracycline consolidation courses followed by ATRA-methotexate-6-mercaptopurine maintenance for 2 years were used in APL.

Both RT and RN were detected in 34 patients. RT was more frequent in favorable cytogenetic categories [i.e. $t(15 ; 17)$ or variants, $t(8 ; 21)$, inv(16)] and the normal karyotype. The frequency of RT was $11 / 31,6 / 19$, and 5/50 in patients with favorable cytogenetic categories, a normal karyotype, and other cases, respectively $(p=0.1)$. The mean age of patients with RT was 7 years younger than those without RT ( $53 \pm 14.4$ vs. $46 \pm 14.6, \mathrm{p}=0.04)$. There were no differences with respect to gender, leukemia type, or ECOG performance status between the two groups. There was no correlation between RT and RN ( $\mathrm{p}=0.09$, $r=0.17)$. 
Table 1. Essential baseline characteristics of patients with AML

\begin{tabular}{|c|c|}
\hline Median age (range), years & $51(21-81)$ \\
\hline \multicolumn{2}{|l|}{ Gender } \\
\hline Female & 43 \\
\hline Male & 57 \\
\hline Reinduction (yes/no) & $12 / 88$ \\
\hline \multicolumn{2}{|l|}{ Cytogenetic group } \\
\hline $\mathrm{t}(8 ; 21)$ & 9 \\
\hline $\operatorname{inv}(16)$ & 7 \\
\hline $\mathrm{t}(15 ; 17)$ or variants & 15 \\
\hline Normal karyotype & 19 \\
\hline Other & 50 \\
\hline \multicolumn{2}{|l|}{ ECOG performance score } \\
\hline 0 & 32 \\
\hline 1 & 52 \\
\hline 2 & 12 \\
\hline 3 & 3 \\
\hline 4 & 1 \\
\hline \multicolumn{2}{|l|}{ WBC at diagnosis $>30 \times 10^{9} / 1$} \\
\hline No & 65 \\
\hline Yes & 35 \\
\hline \multicolumn{2}{|l|}{ Induction protocol } \\
\hline $3+7$ & $82^{\mathrm{a}}$ \\
\hline Including high-dose cytarabine & $3^{\mathrm{b}}$ \\
\hline Idarubicin + all-trans-retinoic acid & 15 \\
\hline \multicolumn{2}{|l|}{$\mathrm{RN}$} \\
\hline No & 66 \\
\hline Yes & 34 \\
\hline \multicolumn{2}{|l|}{ RT } \\
\hline No & 66 \\
\hline Yes & 34 \\
\hline \multicolumn{2}{|l|}{$\mathrm{RT}>525 \times 10^{9} / 1$} \\
\hline No & 78 \\
\hline Yes & 22 \\
\hline \multicolumn{2}{|l|}{ Mean PRT $( \pm S D)$, days } \\
\hline $\mathrm{RT}_{525}$ group & $10.2 \pm 5.1$ \\
\hline $\mathrm{No}-\mathrm{RT}_{525}$ group & $12.7 \pm 8.5$ \\
\hline \multicolumn{2}{|l|}{ Mean NRT $( \pm S D)$, days } \\
\hline RN group & $15.8 \pm 7.7$ \\
\hline No-RN group & $20.3 \pm 9.7$ \\
\hline
\end{tabular}

Values are presented as numbers unless otherwise stated. ${ }^{\text {a }}$ Idarubicin + cytarabine in 75 patients, mitoxantrone + cytarabin in 6 patients and daunorubicin + cytarabine in 1 patient. ${ }^{b}$ Etoposide + mitoxantrone + high-dose cytarabine in 1 patient, and high-dose cytarabine + mitoxantrone in 2 patients.

\section{Independent Prognostic Value of RT and RN in All Patients}

In univariate analyses, the factors that affected OS were residual disease ( $\geq 10 \%$ marrow blasts) in the interim assessment ( $\mathrm{p}=0.001)$, first CR after reinduction therapy $(\mathrm{p}=0.001)$, ECOG performance score at diagnosis $(\mathrm{p}=$ $0.039)$, cytogenetic risk category $(\mathrm{p}=0.034), \mathrm{RT}_{525}$ ( $\mathrm{RT}$ threshold of $\left.525 \times 10^{9} / \mathrm{l}, \mathrm{p}=0.002\right)$, and baseline WBC
$>30 \times 10^{9} / 1(\mathrm{p}=0.064)$. Cox regression analysis using need for reinduction chemotherapy as a stratification parameter revealed $\mathrm{RT}$ as the only parameter to predict OS, with borderline statistical significance $(\mathrm{p}=0.06, \mathrm{OR}=7$; $95 \%$ CI 0.92-53). In univariate analyses, DFS was related to residual disease in the interim marrow assessment $(\mathrm{p}=$ $0.001)$, first CR after reinduction therapy $(\mathrm{p}=0.001)$, ECOG performance score $(\mathrm{p}=0.001), \mathrm{RT}(\mathrm{p}=0.002)$, and leukemia type (CBF-type, APL, and others) $(\mathrm{p}=0.048)$. Cox regression analysis using need for reinduction chemotherapy as a stratification parameter again revealed that RT was the only parameter to predict DFS ( $p=0.024$, $\mathrm{OR}=10 ; 95 \%$ CI 1.3-75).

After understanding that $\mathrm{RT}_{525}$ is an independent prognostic parameter in AML patients, we tried to find its prognostics value in homogeneous cytogenetic/biologic subgroups.

\section{Prognostic Value of $R T_{525}$ in APL Patients}

There were 15 APL patients. The prognostic value of $\mathrm{RT}_{525}$ could not be determined due to low event rates. Only 2 patients experienced an event. Both events were death during consolidation. There was 1 death each in the $\mathrm{RT}_{525}$ and no- $\mathrm{RT}_{525}$ groups.

\section{Prognostic Value of $R T_{525}$ in CBF-Type AML Patients}

There were 16 CBF-type AML patients. Four patients experienced an event. All events were relapses. All 4 events occurred in 12 cases without $\mathrm{RT}_{525}$ while none of the $4 \mathrm{pa}$ tients with $\mathrm{RT}_{525}$ experienced an event. However, statistical significance was not observed between groups in DFS (fig. 1) and OS comparisons due to low event rates ( $\mathrm{p}=$ 0.17 and $\mathrm{p}=0.18$, respectively).

\section{Prognostic Value of $R T_{525}$ in Other AML Patients}

There were 35 events (25 relapses and 10 deaths in $\mathrm{CR})$. All of the events occurred in the no- $\mathrm{RT}_{525}$ group. All $\mathrm{RT}_{525}$ cases in this group were living with $\mathrm{CR}$ at the last follow-up. Both DFS [median (95\% CI): not reached vs. $13.2(6.1-20.2)$ months, $\mathrm{p}=0.004$ ] (fig. 2) and OS [not reached vs. $17.0(0-34.6)$ months, $\mathrm{p}<0.001]$ rates were higher in $\mathrm{RT}_{525}$ cases.

\section{Mechanisms of RT and RN: Better Marrow Capacity or Delayed Consolidation?}

In order to understand whether RT or RN was related to a better marrow capacity or late consolidation, we considered NRT and PRT and nadir-first consolidation durations in all patients in the cohort. In the RT group, the PRT was $10.3 \pm 5.2$ days, whereas it was $12.8 \pm 8.5$ days 


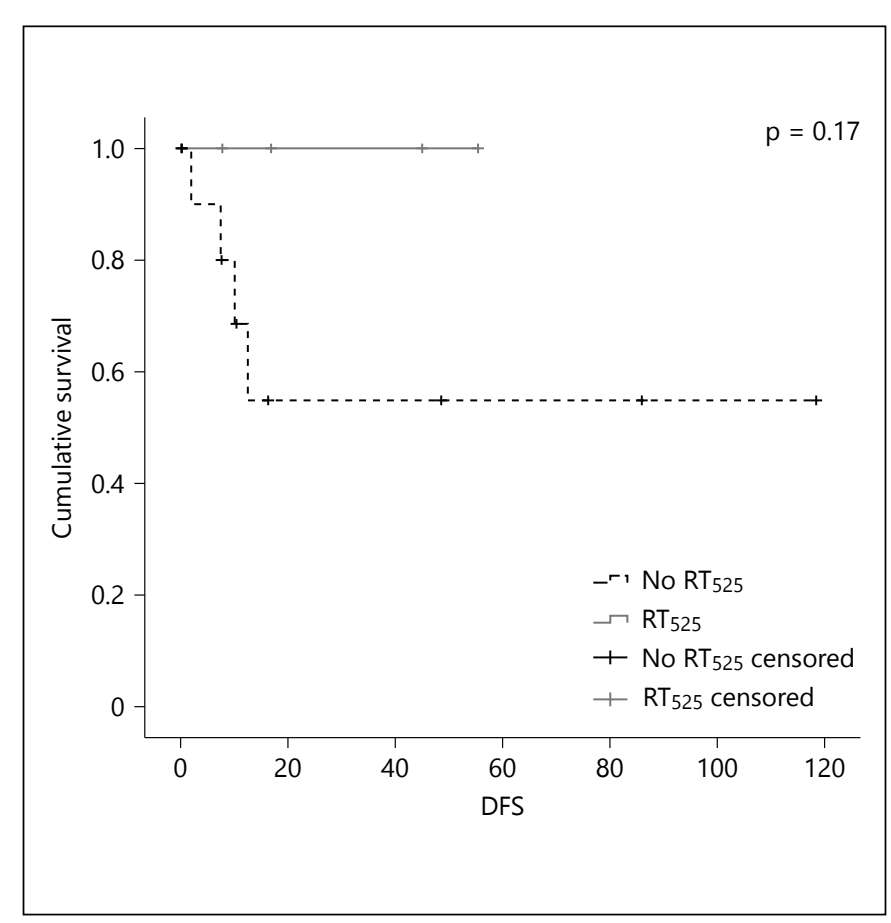

Fig. 1. DFS in CBF-type AML patients with or without $\mathrm{RT}_{525}$.

in the no-RT group $(\mathrm{p}=0.43)$. The NRT was $15.8 \pm 7.8$ and $20.3 \pm 9.7$ days in $\mathrm{RN}$ and no- $\mathrm{RN}$ group, respectively $(\mathrm{p}=0.07)$. In the RT group, the platelet nadir-to-first consolidation time was $27.8 \pm 7.9$ days, whereas it was $29.1 \pm 15.2$ days in the group with no-RT $(\mathrm{p}=0.07)$. The neutrophil nadir-to-first consolidation time was $30.2 \pm$ 11.2 and $34.6 \pm 18.2$ days in the $\mathrm{RN}$ and no-RN groups, respectively $(p=0.12)$. Based on these results, both the marrow recovery duration and the time between marrow aplasia and first consolidation were shorter in RT and $\mathrm{RN}$ patients.

\section{Discussion}

Different clinical and biological features at diagnosis and after induction chemotherapy have been described in patients with AML [1]. Many large multicenter trials have demonstrated that age and cytogenetics [13] at diagnosis are the most important prognostic determinants. Early blast clearance after induction chemotherapy represents a further important factor of potential utility for clinical practice $[1,8,14,15]$. To our knowledge, this is the first study to report a correlation between RT/RN and prognosis in AML. Interestingly, RT was the only significant independent parameter in multivariate analyses also in-

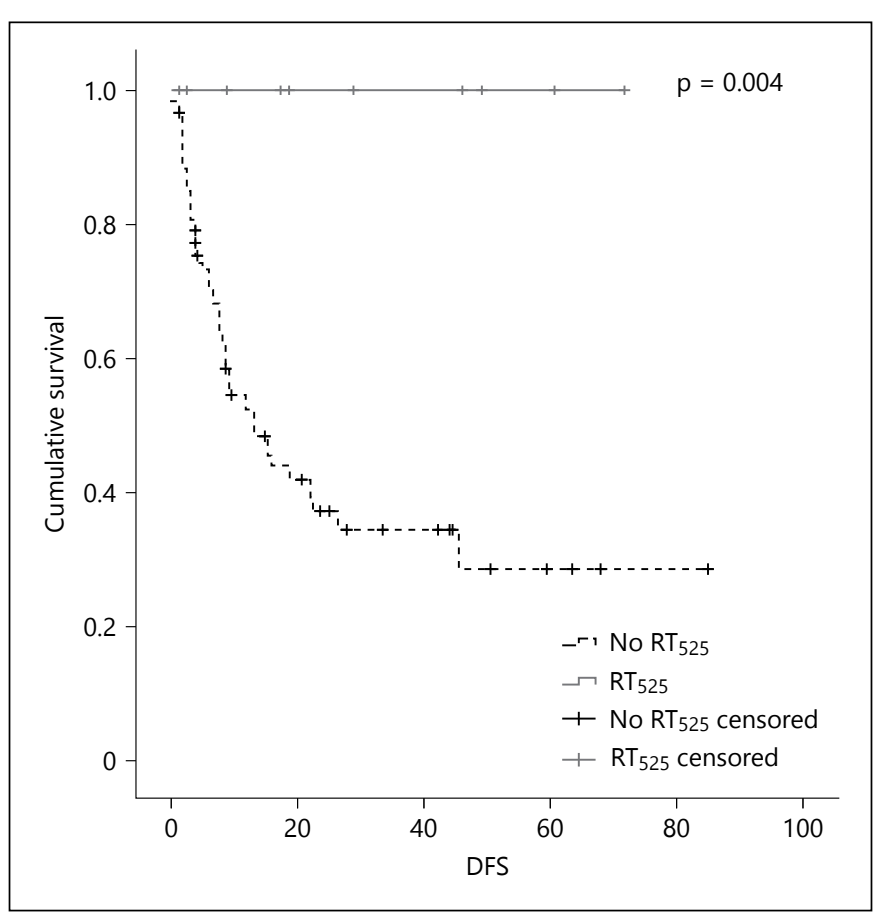

Fig. 2. DFS in other AML patients with or without $\mathrm{RT}_{525}$.

cluding classical prognostic risk factors for OS and DFS. The favorable prognosis associated with $\mathrm{RT}_{525}$ was evident in AML patients other than those with APL and CBF-type disease. However, it could not be demonstrated in APL and CBF-type disease probably due to low event rates. In accordance with this suggestion, there was a trend towards statistical significance in CBF-type disease (0/4 vs. 4/12 relapses in $\mathrm{RT}_{525}$ and no- $\mathrm{RT}_{525}$ cases, respectively, $\mathrm{p}=0.17$ ).

The prognostic significance of clinicopathological parameters such as age, hematological antecedent, WBC count, liver enlargement, and Auer rods has been confirmed in previous AML studies $[2,7,13,16,17]$. Moreover, high platelet and polymorphonuclear counts have also previously appeared to be of interest for determining therapeutic aggressiveness [16]. In our present study, the marrow recovery time and the duration between marrow aplasia and first consolidation were shorter in RT and RN cases, indicating a better healthy hematopoiesis/marrow capacity in this group. As RT and RN are very easy to detect, they can be used as prognostic indicators in countries with limited laboratory facilities. Our results support the impression that an accelerated platelet and WBC recovery following chemotherapy could be accepted as a promising sign of a good prognosis and thus the future response to therapy in AML. 
Platelet kinetics, functions, TPO, and thrombocytosis are usual parts of acute and chronic neoplastic myeloproliferative diseases $[11,12,18-23]$. AML prognosis and bone marrow recovery following chemotherapy are related to cellular kinetics $[9,10]$ and blast clearance $[1,8$, $14,15]$. Previous investigations focusing on endogenous TPO dynamics in association with platelets during the clinical course of AML have indicated significantly increased TPO during the aplastic period due to remission induction chemotherapy in AML. Thus, endogenous TPO exhibits inverse fluctuation in relation to platelet counts during the clinical course of AML [11]. TPO has the potential to cause RT and to affect stem cells as well as leukemic blast cells $[11,12,21,22]$. In our current study, we found that both bone marrow recovery duration and the time between marrow aplasia and first consolidation were shorter in AML patients with RT and RN. The relationships between hematopoietic cytokines, particularly TPO, and thrombopoietic kinetics following chemotherapy should be further examined in the context of AML prognosis. Early assessment using flow cytometry could also provide additional prognostic information to refine risk stratification in AML [24-27].

The application of advanced molecular techniques, such as gene and microRNA expression profiling, whole genome and exome sequencing, proteomic analysis, and methylation assays, has allowed the identification of recurrent molecular abnormalities in AML, but their impact on the prediction of the prognosis is not yet standardized [3, 28]. Next-generation highest-technology tools can be useful for classifying phenotypes, detecting the presence of $M R D$, discriminating among disease subtypes, predicting clinical outcomes, and characterizing disease progression [29]. However, availability, cost, standardization, and validation have made their use challenging. Resistance predictions in AML were recently analyzed in 4,601 AML patients from the major leukemia groups including MRC/NCRI, HOVON/SAKK, SWOG, and MDACC [7]. That multicenter study concluded that the ability to predict therapeutic resistance in AML, based on the routinely available clinical covariates, even with the inclusion of commonly used molecular data on FLT3 and NPM1, is relatively limited [7]. Likewise, the relationship between a poor prognosis and residual blasts 7-10 days after induction therapy in AML is well known, and this evaluation is widely applied in clinical practice for early reinduction [8]. Walter et al. [30] demonstrated that $\mathrm{CR}$ with incomplete platelet recovery was associated with a worse prognosis in AML patients receiving cytrarabinebased induction therapy. This finding is related to our results from an opposite angle. Insufficient platelet recovery indicates a worse prognosis while exaggerated platelet recovery is associated with a good prognosis [30]. In accordance with the above mentioned studies, our present investigation revealed that RT following induction chemotherapy is an independent predictor of a good prognosis in AML patients attaining first CR. This conclusion is important for better management of and clinical decision-making regarding patients with AML. Therefore, our findings should be confirmed in further patient cohorts and/or preferably within the context of prospective studies.

\section{References}

1 Ferrara F, Palmieri S, Leoni F: Clinically useful prognostic factors in acute myeloid leukemia. Crit Rev Oncol Hematol 2008;66:181193.

2 Yanada M, Garcia-Manero G, Borthakur G, Ravandi F, Kantarjian H, Estey E: Relapse and death during first remission in acute myeloid leukemia. Haematologica 2008;93:633-634.

3 Bhatnagar B, Garzon R: The use of molecular genetics to refine prognosis in acute myeloid leukemia. Curr Hematol Malig Rep 2014;9: 148-157.

4 Inaba H, Coustan-Smith E, Cao X, Pounds SB, Shurtleff SA, Wang KY, Raimondi SC, Onciu M, Jacobsen J, Ribeiro RC, Dahl GV, Bowman WP, Taub JW, Degar B, Leung W, Downing JR, Pui CH, Rubnitz JE, Campana D: Comparative analysis of different approaches to measure treatment response in acute myeloid leukemia. J Clin Oncol 2012;30:3625-3632.
5 Kim DY, Lee JH, Sym SJ, Yun SC, Lee JH, Kim SD, Choi Y, Lee YS, Kang YA, Jeon M, Seol M, Lee KH, Lee YJ, Lee KH: A prediction model for complete remission upon reinduction for patients with acute myeloid leukemia after failure of anthracycline and cytarabine standard chemotherapy. Ann Hematol 2011;90: 1283-1291.

6 Walter RB, Othus M, Borthakur G, Ravandi F, Cortes JE, Pierce SA, Appelbaum FR, Kantarjian HA, Estey EH: Prediction of early death after induction therapy for newly diagnosed acute myeloid leukemia with pretreatment risk scores: a novel paradigm for treatment assignment. J Clin Oncol 2011;29:44174423.

7 Walter RB, Othus M, Burnett AK, Löwenberg B, Kantarjian HM, Ossenkoppele GJ, Hills RK, Ravandi F, Pabst T, Evans A, Pierce SR, Vekemans MC, Appelbaum FR, Estey EH:
Resistance prediction in AML: analysis of 4,601 patients from MRC/NCRI, HOVON/ SAKK, SWOG and M. D. Anderson Cancer Center. Leukemia 2014, DOI: 10.1038/ leu.2014.242.

8 Haferlach T, Kern W, Schoch C, Schnittger S, Sauerland MC, Heinecke A, Büchner T, Hiddemann W; German AML Cooperative Group: A new prognostic score for patients with acute myeloid leukemia based on cytogenetics and early blast clearance in trials of the German AML Cooperative Group. Haematologica 2004;89:408-418.

9 Yanada M, Borthakur G, Garcia-Manero G, Ravandi F, Faderl S, Pierce S, Kantarjian $\mathrm{H}$, Estey E: Blood counts at time of complete remission provide additional independent prognostic information in acute myeloid leukemia. Leuk Res 2008;32:15051509. 
10 Yanada M, Borthakur G, Ravandi F, BuesoRamos C, Kantarjian H, Estey E: Kinetics of bone marrow blasts during induction and achievement of complete remission in acute myeloid leukemia. Haematologica 2008;93: 1263-1265.

11 Gonen C, Haznedaroglu IC, Aksu S, Koca E, Göker H, Büyükaşik Y, Sayinalp N, Ozcebe O, Dündar S: Endogenous thrombopoietin levels during the clinical management of acute myeloid leukaemia. Platelets 2005; 16 : 31-37.

12 Haznedaroglu IC, Goker H, Turgut M, Buyukasik Y, Benekli M: Thrombopoietin as a drug: biologic expectations, clinical realities, and future directions. Clin Appl Thromb Hemost 2002;8:193-212.

13 Yanada M, Garcia-Manero G, Borthakur G, Ravandi F, Kantarjian H, Estey E: Potential cure of acute myeloid leukemia: analysis of 1,069 consecutive patients in first complete remission. Cancer 2007;110:2756-2760.

14 Elliott MA, Litzow MR, Letendre LL, Wolf RC, Hanson CA, Tefferi A, Tallman MS: Early peripheral blood blast clearance during induction chemotherapy for acute myeloid leukemia predicts superior relapse-free survival. Blood 2007;110:4172-4174.

15 Vainstein V, Buckley SA, Shukron O, Estey EH, Abkowitz JL, Wood BL, Walter RB: Rapid rate of peripheral blood blast clearance accurately predicts complete remission in acute myeloid leukemia. Leukemia 2014;28:713716.

16 Delmer A, Marie JP, Thevenin D, Cadiou M, Viguie F, Zittoun R: Multivariate analysis of prognostic factors in acute myeloid leukemia: value of clonogenic leukemic cell properties. J Clin Oncol 1989;7:738-746.

17 Yanada M, Ohtake S, Miyawaki S, Sakamaki H, Sakura T, Maeda T, Miyamura K, Asou N, Oh I, Miyatake J, Kanbayashi H, Takeuchi J, Takahashi M, Dobashi N, Kiyoi H, Miyazaki
Y, Emi N, Kobayashi Y, Ohno R, Naoe T; Japan Adult Leukemia Study Group: The demarcation between younger and older acute myeloid leukemia patients: a pooled analysis of 3 prospective studies. Cancer 2013;119: 3326-3333.

18 Acar K, Aksu S, Beyazit Y, Haznedaroglu IC, Koca E, Cetiner D, Sayinalp N, Buyukasik Y, Goker H, Kirazli S, Ozcebe OI: Soluble platelet glycoprotein $\mathrm{V}$ in distinct disease states of pathological thrombopoiesis. J Nat Med Assoc $2008 ; 100: 86-90$.

19 Asik M, Karakus S, Haznedaroglu IC, Goker H, Ozatli D, Buyukasik Y, Sayinalp N, Ozcebe OI, Kirazli S: Bone marrow and peripheral blood C-kit ligand concentrations in patients with thrombocytosis and thrombocytopenia. Hematology 2003;8:369-373.

20 Haznedaroglu IC: The therapeutic goals of essential thrombocythemia under the clouds of over-treatment and under-treatment. Expert Opin Pharmacother 2013;14:1431-1436.

21 Haznedaroğlu IC, Atalar E, Oztürk MA, Ozer N, Ovünç K, Aksöyek S, Kes S, Kirazli S, Ozmen F: Thrombopoietin inside the pulmonary vessels in patients with and without pulmonary hypertension. Platelets 2002;13:395399.

22 Karakuş S, Ozcebe OI, Haznedaroğlu IC, Göker H, Ozatli D, Koşar A, BüyükașIk Y, Ertuğrul D, SayInalp N, KirazlI S, Dündar SV: Circulating thrombopoietin in clonal versus reactive thrombocytosis. Hematology 2002;7: 9-12.

23 Ulger Z, Aksu S, Aksoy DY, Koksal D, Haznedaroglu IC, Kirazli S: The adhesion molecules of L-selectin and ICAM-1 in thrombocytosis and thrombocytopenia. Platelets 2010;21:4952.

24 Freeman SD, Virgo P, Couzens S, Grimwade D, Russell N, Hills RK, Burnett AK: Prognostic relevance of treatment response measured by flow cytometric residual disease detection in older patients with acute myeloid leukemia. J Clin Oncol 2013;31:4123-4131.

25 Köhnke T, Sauter D, Ringel K, Hoster E, Laubender RP, Hubmann M, Bohlander SK, Kakadia PM, Schneider S, Dufour A, Sauerland MC, Berdel WE, Büchner T, Wörmann B, Braess J, Hiddemann W, Spiekermann K, Subklewe M: Early assessment of minimal residual disease in AML by flow cytometry during aplasia identifies patients at increased risk of relapse. Leukemia 2014, DOI: 10.1038/ leu.2014.186.

26 Webber BA, Cushing MM, Li S: Prognostic significance of flow cytometric immunophenotyping in acute myeloid leukemia. Int J Clin Exp Pathol 2008;1:124-133.

27 Xu XJ, Feng JH, Tang YM, Shen HQ, Song H, Yang SL, Shi SW, Xu WQ: Prognostic significance of flow cytometric minimal residual disease assessment after the first induction course in Chinese childhood acute myeloid leukemia. Leuk Res 2013;37:134-138.

28 Forshed J, Pernemalm M, Tan CS, Lindberg M, Kanter L, Pawitan Y, Lewensohn R, Stenke L, Lehtiö J: Proteomic data analysis workflow for discovery of candidate biomarker peaks predictive of clinical outcome for patients with acute myeloid leukemia. J Proteome Res 2008;7:2332-2341.

29 Eddy JA, Sung J, Geman D, Price ND: Relative expression analysis for molecular cancer diagnosis and prognosis. Technol Cancer Res Treat 2010;9:149-159.

30 Walter RB, Kantarjian HM, Huang X, Pierce SA, Sun Z, Gundacker HM, Ravandi F, Faderl SH, Tallman MS, Appelbaum FR, Estey EH: Effect of complete remission and responses less than complete remission on survival in acute myeloid leukemia: a combined Eastern Cooperative Oncology Group, Southwest Oncology Group, and M. D. Anderson Cancer Center Study. J Clin Oncol 2010;28:17661771. 